\title{
Retrospective Analysis of Preperitoneal MeshRepair in Incisional Hernia-A 3years Study
}

\author{
Mohammed Arif ${ }^{*}$, Dhananjaya Kumar B.R ${ }^{2}$ \\ ${ }^{I^{*}}$ (Associate Professor in Surgery, SIMS, Shimoga / RGUHS Karnataka state, INDIA) \\ ${ }^{2}$ (Senior Resident in Surgery, SIMS, Shimoga / RGUHS Karnataka state, INDIA)
}

\begin{abstract}
:
Background and objective:

Incisional hernia is one of the most common problems encountered by general surgeons worldwide. Many forms of repair have been adopted with their own merits and demerits. In thisretrospective study, an attempt is made to evaluate theoutcome of preperitoneal mesh repair of incisional hernia with reference to technicaldifficulty, convalescence, wound infection, bowel adhesions, intestinal obstruction, intestinal fistula formation and recurrence.
\end{abstract}

Methods:

Study includes detailed clinical evaluation and management of 25 randomly selectedcases of incisional hernia treated with pre-peritoneal polypropylene mesh repair in incisional hernias in Shimoga Institute of Medical Sciences, Shimoga during last 3 years period.

Results:

The majority of patients were in the age group of 21-30 years. Incidence was more common in females than males. Most common symptom was mass per abdomen. $68 \%$ patients presented withherniation of abdominal wall within 2 years of previous laparotomy. $76 \%$ of our patients had defect sizeof $1-5 \mathrm{~cm}$ in diameter. Average time takenfor repair was about 60 minutes. No technical difficulty was encountered inperforming preperitoneal mesh repair. All thecases were followed up for a periodof 1 year and no recurrence was noted in our limited study population.

Conclusion:

Incisional hernia is a common surgical condition with a reported incidence of 2 to $11 \%$ following all laparotomies. Various types of repair have been described,both anatomical and prosthetic. Based on our study we conclude that, the operation ofpre-peritoneal mesh repair for incisional hernia, if done meticulously will have no recurrence rate and no complications.

Keywords: preperitoneal, incisional hernia, complications, recurrence.

\section{Introduction}

An incisional hernia indicates the protrusion of viscera from the abdominal cavity through a route formed after trauma induced by cutting [1]. Incidence of post- operative hernia has been at least $10 \%$.in most of institutions [2].Incisional hernias of the perineum and coccyx have also been reported. Many factors singly or in various combinations may cause failure of the wound to heal satisfactorily and may lead to the development of incisional hernia. The two main causes are poor surgical technique and sepsis, others causes being obesity, patients with persistent post-operative cough, patients with postoperative abdominal distension etc. The hernia especially through a lower abdominal scar usually increasessteadily in size and gradually becomes irreducible. Thesetypes of hernias can result sometimes in incarceration (6-15\%) and strangulation of contents (2\%).Unfortunately recurrence rate after primary anatomical repair ranges from $20 \%-40 \%$ [3]. The use of sheets of non-absorbable synthetic mesh prostheses placed across the defect and stitched to the abdominal wall has revolutionized the repair of abdominal wall defects and brought down the recurrence to $10 \%$. This being a retrospective study, examines the various risk factors involved in causation of incisional hernia, its varied clinical presentations and the role of pre-peritoneal polypropylene mesh repair in its management.

\section{Patients And Methods}

This study includes all cases of incisional hernia selected randomly over the last 3 years period in our institution.Patients with strangulated and incarcerated hernias, intra-abdominalmalignancies and patients with severe co-morbid conditions (severe cardio-pulmonarydisease, uncontrolled ascites) and pregnant women with incisional hernias are excludedfrom the study.

Clinical history was taken regarding duration of hernia, progression in size, associated complaints like pain in the swelling or abdomen, vomiting, reducibility, chronic cough, constipation, difficulty in micturition, abdominal distension, historysuggestive of ascites and other causes of abdominal distension, number 
ofpregnancies etc. History regarding previous surgery with respect to nature of operation,duration, type of incision, type of closure, post-op complications, was enquired.

In local examination special attention was given to the position, size, shape, In routine general physical examination attention was given to obesity,hypertension, anaemia, hypoprotenemia, jaundice, tone of the abdominal muscles, in finding the cause of abdominal distension, per-rectal examination to look formass(malignancy) in the rectum, benign prostatic enlargement, examination to look forexternal meatal stenosis and stricture urethra in males. Respiratory systemexamination was done to look for rhonchi, crepitations suggestive of COPD.Patient was defined as diabetic if patient had been diagnosed as diabeticearlier and was on treatment or if the patient's blood sugar was greater than normal.Hypertension in this study was defined as, patients who were diagnosed ashypertensive and were on treatment or those patients whose blood pressure wasgreater than $140 / 90 \mathrm{mmHg}$ on 3 consecutive days. Obesity was defined as body mass index of more than 30 in both men andwomen. Multiparity was defined as females having more than 2 children.

All cases included in the studyunderwent pre-operative investigations in the form of $\mathrm{Hb} \%, \mathrm{BT}, \mathrm{CT}$, FBS, PPBS, Blood Urea, Serum creatinine, Urine Routine, ECG, Chest X ray and Ultrasonography (soft tissue scansas well abdomino-pelvic USG).

Informed written consent was obtained after explaining the surgicalprocedure, its results and complications.All patients received one dose of preoperative antibiotic $1 \mathrm{gm}$ of 3rd generationcephalosporins during or immediately after induction of anaesthesia. Urinary bladderwas catheterized for all patients. Patients were operated either under spinalanaesthesia or general anaesthesia. On operating table povidone iodine scrub was applied to the anterior abdominal wall.

Pre -peritoneal mesh repairprocedure:Under anaesthesia patients were laid on her/his back, parts painted and drapes were applied around the hernial defect including the previous scar. A transverse/vertical ellipticalincision was made enclosing the previous operated scar. The old scar was excised and the hernial sac dissected free down to the myoaponeurotic edges. The sac is then opened and its contents inspected. If the content was omentum, and if it was ischemic/devitalized after releasing the adhesions it was ligated and omentectomy done. Healthy omentum was returned into the peritoneal cavity. The excess sac was excised. Peritoneum and sac are separated from the posterior rectus sheath well beyond the actual defect, all around carefully and meticulously. After preparing the bed for mesh placement, peritoneum and sac are closed with a running absorbable synthetic suture. Polypropylene meshes longer than the length of the defect was placed over the peritoneum. Mesh was fixed under slight tension with non-absorbable monofilament synthetic suture (polypropylene 1-0), to the musculo-aponeurotic sheath by putting ' $U$ ' stitches, so that the knots come to lie on the outer surface of the external oblique muscle/musculoaponeurotic sheath. A vacuum drain (NO.16) was laid on the graft and brought out through a separate stab wound. The two rectus sheaths are sutured together along their medial edges with a continuous synthetic non-absorbable monofilament suture. Another vacuum drain was laid on the rectus sheath and brought through separate stab wound. The excess skin was excised and the wound was closed in layers.

Fig 1: A case of incisional hernia .

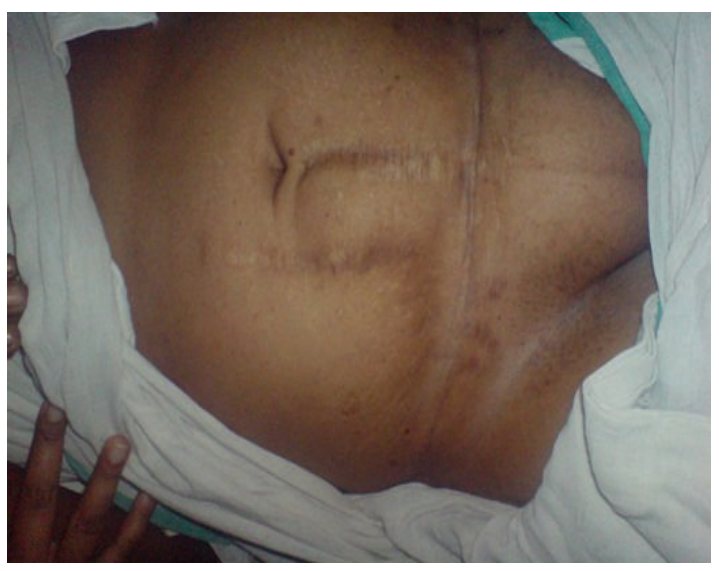

Fig 2: Hernial sac dissected and exposed.

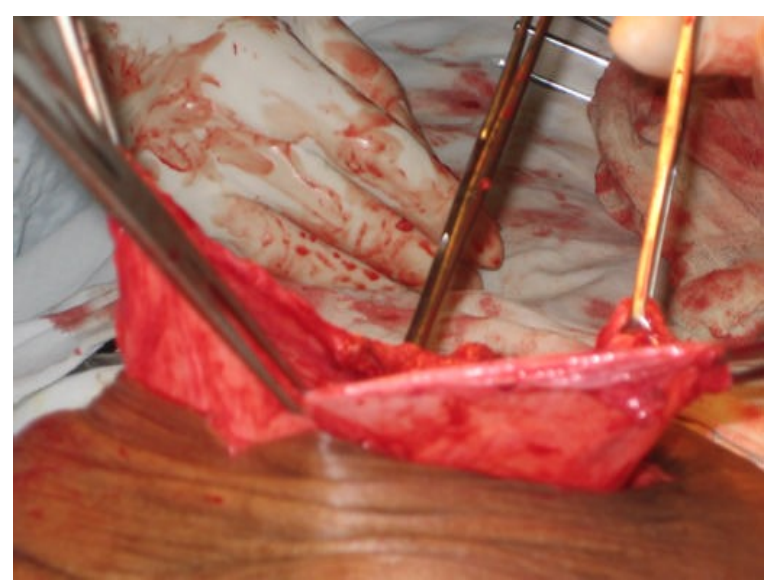


Fig 3: Peritoneum is closed with no. 2-0 vicryl.Fig 4: Prolene mesh in pre -peritoneal space.
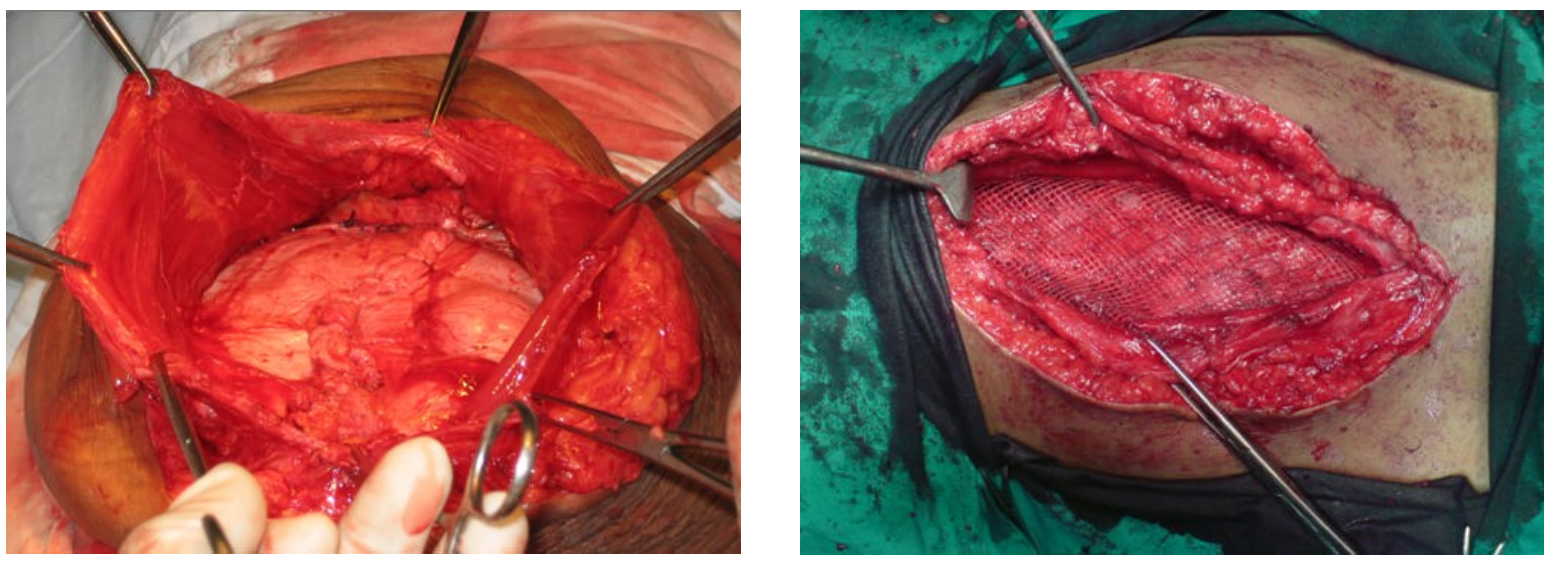

Fig 5: Rectus sheath closed with no. 1 prolene sutureFig 6: Skin closed with vertical mattress suture.
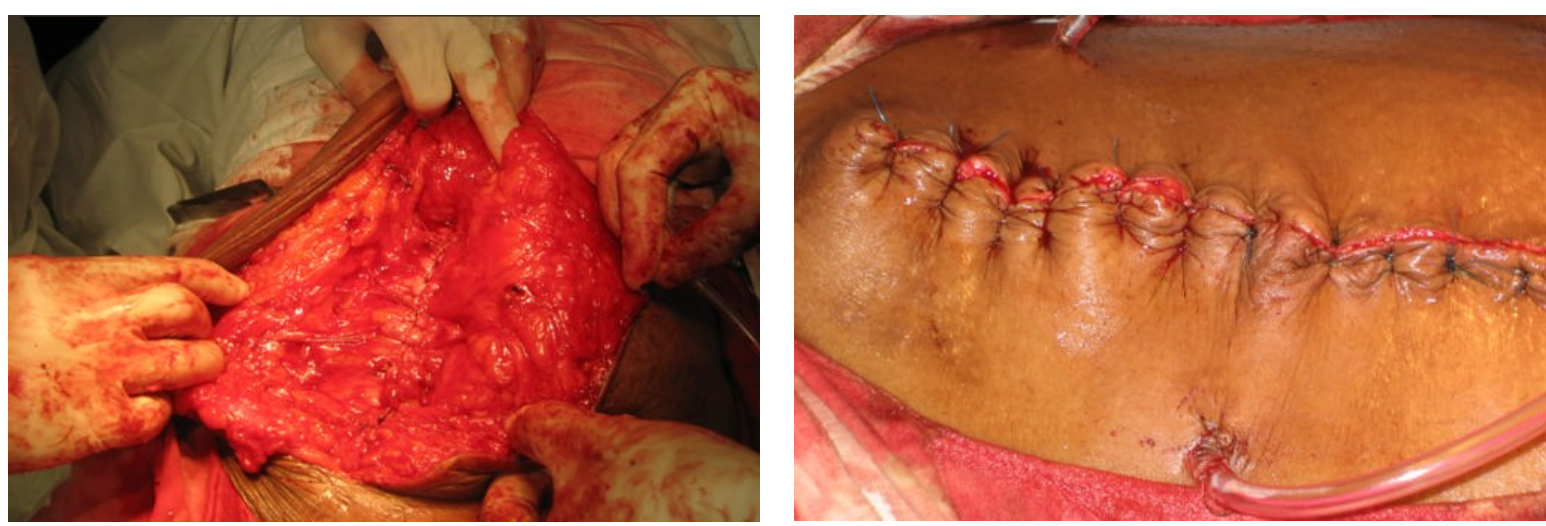

Post-operative infection in our study was defined as presence of erythema ofgreater than $1 \mathrm{~cm}$ from wound margins, tenderness on palpation and presence of seropurulent /purulent discharge. Sutures were removed about 7-8 days after the surgery.

The patients were followed up atone month, six months and after a year for any complications or recurrence.

\section{Results And Observations}

The majority of patients were in the age group of 21-30 years.In this study, the youngest patient was 22 years old and oldest was 76years old.In our study $96 \%$ of patients presented with infra umbilical swelling. $4 \%$ presented with supra umbilical swelling. The following is the summary of observations in study group:

- Incisional hernia was more commonly seen in 3rd decade of life.

- It was more common in females (88\%) than in males (12\%). Female: male ratio being 8.8:1.2.

- The most common symptom was swelling in the abdomen, with or without pain.

- In majority (52\%) of the patients, the incisional hernia occurred within one year of previous surgery.

- Size of the hernial defect varied from $1 \mathrm{~cm}$ to more than $10 \mathrm{cms}$ in diameter. Defect was $1-5 \mathrm{~cm}$ in $76 \%$ of patients, between $5-10 \mathrm{~cm}$ in another $20 \%$ of patients and more than $10 \mathrm{~cm}$ in $4 \%$ of patients.

- All cases were treated by preperitoneal polypropylene mesh repair.

- No technical difficulty was observed in any of the cases.

- Duration of surgery varied with each case. Average time taken in $76 \%$ patients was about 60 minutes.

- Most common post-operative complication was seroma, seen in 3 patients out of 25 operated cases.

- Use of closed suction tube drain considerably reduced the post -operative morbidity by reducing the incidence of seroma formation, hematoma formation and also the incidence of wound infection.

- Time taken to resume normal activity was 12 to 18 days in majority of patients.

- All patients were followed up for a minimum period of one year. 
- There were no recurrences of hernia found in the specified follow up period. In the present study, convalescence period in $76 \%$ patients was between 12 to 18 days, where as $24 \%$ patients it was more than 18 days.

TABLE 1:Age distribution of incisional hernia cases in our study

\begin{tabular}{|c|c|c|}
\hline Age in years & No. of cases & Percentage \\
\hline $21-30$ & 07 & $28 \%$ \\
\hline $31-40$ & 06 & $24 \%$ \\
\hline $41-50$ & 04 & $16 \%$ \\
\hline $51-60$ & 06 & $24 \%$ \\
\hline $61-70$ & 01 & $04 \%$ \\
\hline $71-80$ & 01 & $04 \%$ \\
\hline
\end{tabular}

TABLE 2:Sex incidence of incisional hernia cases in our study

\begin{tabular}{|c|c|c|}
\hline Sex & No. of cases & Percentage \\
\hline Male & 3 & $12 \%$ \\
\hline Female & 22 & $88 \%$ \\
\hline
\end{tabular}

TABLE 3:Time of onset of incisional hernia after previous operation.

\begin{tabular}{|c|c|c|}
\hline Time of onset & No. of cases & Percentage \\
\hline Within 1 year & 13 & $52 \%$ \\
\hline $1-2$ years & 4 & $16 \%$ \\
\hline $2-5$ years & 4 & $16 \%$ \\
\hline More than 5 years & 4 & $16 \%$ \\
\hline
\end{tabular}

TABLE 4: Nature and types of incisions of previous surgery

\begin{tabular}{|c|c|c|c|}
\hline Type of Incision & Previous Surgery procedure & No. of cases & Percentage \\
\hline Lower midline & Hysterectomy & 4 & Total 16 (64\%) \\
& Tubectomy & 8 & \\
\hline Light paramedian & Laparotomy & 3 & $12 \%$ \\
\hline Pfannensteil & L S C S & 4 & Total 5 (20\%) \\
\hline Upper midline & Hysterectomy & 1 & $4 \%$ \\
\hline
\end{tabular}

\section{Discussion}

Incisional hernia is one of the most common conditions requiring major surgery. The reported incidence in literature is 2-11\% following all laparotomies [4]. Mudge $\mathrm{M}$ et al in 1985 in his series "incisional hernia; ten year prospective study of incidence and attitudes" reported an incidence of $11 \%$ [5]. Bucknall TE et al reported an incidence of $23 \%$ in those patients who developed postoperative wound infections [6].

In order to assess and apply the proper repair technique in incisional hernia, the pathophysiologic basis of herniation should be well understood. Collagen constitutes approximately one -third of the total protein content of any organism and is the predominant structural protein of the aponeurosis, where it is organized in fibres, whose chemical-physical characteristics render them particularly resistant to traction. Within the abdominal wall, as in other tissue, damaged collagen fibers are repaired through a process of proliferation and remodelling [7]. The aim of MMP proteolytic activity is to permit the passage of macrophages and fibroblasts across hydrolysed collagen fibres, leading to tissue repair where necessary. Metalloprotease inhibitors (TIMPS) limit the excessive destruction of collagen during this process. Nonetheless, if degradation becomes too extensive, MMP inhibition is reduced, and proteolytic activity increased, biochemically pathological situations can be created. This is referred to as "the point of decreased resistance," which corresponds to hernia development [8]. In healthy skin, type I and type III collagens are found in a 4:1 ratio. In patients with incisional hernia, type III collagen may be increased in the skin and aponeurosis. This suggests that a collagen disequilibrium favours the development of incisional hernias, especially in the presence of other cofactors, such 
as age (>60 years), sex (male), incision type, technically incorrect reduction or infection. Other, correlating or patient-dependent risk factors are atherosclerosis, metabolic disorders (obesity, renal insufficiency, protein deficiency, factor VIII coagulation deficiency, vitamin C deficiency, and smoking) [9]. It may emphasised in this context that no wound can be considered completely free from bacterial contamination, although there are a critical number of bacteria above which a clinically evident infection can be seen. This limit corresponds to 105 bacteria per gram of tissue or millilitre of liquid (serum, etc.) [10].

The earliest recorded mention of hernia and its treatment is found in EgyptianEbers Papyrus in 1500BC.Celsius in first century AD was the first to be aware ofincisional hernias. He advised freshening of the tissue edges and uniting them by suture. For the next 2000 years little was added to the study and art of herniology.Major abdominal surgery developed rapidly during the latter part of the 19th century and with it raisedthe incidence of post-operative hernias. For more than 100yearsattempts have been made to develop successful methods for repairing them.In 1972, De Franchispublished a report on incisional hernia surgery that was considered to be a referencepoint due to its abundant bibliographical data and its descriptions of the varioussurgical techniques used in the treatment of incisional hernia, These were based onwhat is considered as the cornerstone of abdominal-wall reconstruction, that is,aponeurotic suturing [11].

Stock (1954) suggested the application of a nylon mesh between the peritoneum and the muscle layer [12]. Polypropylene mesh has been used extensively because it has the greatesttissue ingrowths of all the mesh products available with least complication rate [13]. Recently, theretro- muscular preperitoneal space has emerged as the ideal position for the mesh.This approach, more commonly known as Rivas Stoppa technique became popularduring 1990s. The recurrence rate with this technique has been stated to be $<10 \%$ [14]. In 1986 George CD did a study on 81 cases of incisional hernia using keelrepair and reported a recurrence rate of $46 \%$. In 2001 Khaira HS did a study on 35 cases of incisional hernia usingcombined fascial mesh repair. Over a follow up period of $6-55$ months he reported a recurrence rate of $6 \%$ [15].In 2003 Ferranti F repaired 35 cases of incisional hernia using Rivas Stoppatechnique and reported a recurrence rate of 2.8\% [16].In 2007 Bhat MG studied 105 cases of incisional hernias using preperitonealmesh repair and reported no recurrences and infection over a period of 7 years in aretrospective study [17].In 2003 Langer C did a study on prosthetic repairs on incisional hernia usingsub lay and inlay technique. Over a follow up period of 10 years he reported arecurrence rate of $15 \%$. In 2003 Anton Hamy MD did a study on 350 cases ofincisional hernia using intraperitoneal Dacron mesh and aponeurotic graft andreported a recurrence rate of $3.1 \%$.

The techniques of auto- and heterotransplant of the fascia lata, skin grafting,or of the skin cut into small plastic like strips have also been applied in the treatment ofincisional hernias of small dimensions.

TABLE 5: Postoperative complications seen in our studyin comparison to documented literature.

\begin{tabular}{|l|c|c|c|c|c|}
\hline \multicolumn{1}{|c|}{ Complication } & No. of cases & Percentage & $\begin{array}{c}\text { OHANA et } \\
\text { al [18]. }\end{array}$ & $\begin{array}{c}\text { MATAPURKAR } \\
\text { et al [19]. }\end{array}$ & $\begin{array}{c}\text { BHAT et al } \\
\text { (20) }\end{array}$ \\
\hline $\begin{array}{l}\text { Superficial wound } \\
\text { infection }\end{array}$ & 1 & $4 \%$ & $4(9.3 \%)$ & $10(17 \%)$ & $0 \%$ \\
\hline Seroma & 3 & $12 \%$ & $3(7 \%)$ & 0 & $0 \%$ \\
\hline Intestinal obstruction & 0 & 0 & $1(2.3 \%)$ & $2(3 \%)$ & $0 \%$ \\
\hline Intestinal fistula & 0 & 0 & $4(9.3 \%)$ & 0 & $0 \%$ \\
\hline Bowel adhesions & 0 & 0 & 0 & 0 & 0 \\
\hline
\end{tabular}

TABLE6:Recurrence rate compared with other studies

\begin{tabular}{|c|c|c|}
\hline STUDY & FOLLOW UP & RECCURENCE RATE (\%) \\
\hline Ohana et al $[18]$ & 46 months & $\mathbf{0}$ \\
\hline Matapurkar et al $[19]$ & Variable & $\mathbf{1 2 . 5}$ \\
\hline Bhat M G $[20]-8$ yrs. & 14 months & $\mathbf{0}$ \\
\hline Present study & 1 year & $\mathbf{0}$ \\
\hline
\end{tabular}

\section{Conclusion}

Incisional hernia is a common surgical condition with a reported incidence of 2 to $11 \%$ following all laparotomies. Various types of repair have been described, bothanatomical and prosthetic. The present study aimed at evaluating the technique of preperitoneal mesh repair in incisional hernia. Based on our study we concludethat, the operation of preperitoneal mesh repair for incisional hernia which is easy tolearn, taking an average duration of one hour to perform with shorter convalescentperiod for patients and minimal postoperative complications, and above all withoutany recurrence during the follow up period, is one of the best operations for 
repair of incisional hernia. The follow up period in our study is short. Longer followup is needed to know the true recurrence rate.

Acknowledgements: NIL

Conflict of Interest: None.

Funding : Nil

Ethical Clearance : Not Required.

\section{References}

[1]. Di Vita G, Frazzetta M, Cortese E et al Laparocele dopo chirurgialaparoscopica. Min Chir 1997;52:523-26

[2]. Santora T A, Roslyn J J. Surg Clin North Am 1993; 73: 557-70.

[3]. Flum DR, Hosvath K, koepsel T. Have outcomes of incisional hernia repairimproved with time? A population based analysis. Am $J$ Surg 2003; 23: 129-35.

[4]. Santora TA, Roslyn JJ. Incisional hernia. Surg Clin North Am 1993; 73:557-570

[5]. Mudge M, Huges LE. Incisional hernia: a 10 year prospective study of incidenceand attitudes. Br J Surg 1985; 72 : 70-1.

[6]. Bucknall TE, Cox PJ, Ellis H. Burst abdomen and incisional hernia: a prospectivestudy of 1129 major laparotomies. BMJ 1982; 284: 931-3.

[7]. Sorensen LT, Hemmingsen U, Kallehave F et al Risk factors for tissue andwound complications in gastrointestinal surgery. Ann Surg 2005; 241(4):654-658.

[8]. Lindholt JS, Jorgensen B, Klitgaard NA, Henneberg EW (2003) Systemic levelsof cotinineand elastase, but not pulmonary function, are associated with theprogression of small abdominal aortic aneurysm. Eur J VascEndovascSurg26 (4):418-422.

[9]. Sugerman HJ, Kellum JM Jr, Reines HD et al Greater risk of incisionalhernia with morbidly obese than steroid-dependent patients and low recurrencewith prefascial polypropylene mesh. Am J Surg 1996 171:80-84.

[10]. Heggers JP (1991) Variations on a theme. In: Heggers JP, Robson MC (Eds)Quantitative bacteriology: its role in the armamentarium of the surgeon. CRCPress, Boca Raton, pp15-23.

[11]. Santora T A, Roslyn J J. Surg Clin North Am 1993; 73: 557-70.

[12]. Stock FE Repair of large hernias with nylon. Lancet 1954; 266:395-396.

[13]. Turnage RH, Richardson KA, Li BD, McDonald JC, Abdominal wall, umbilicus, peritoneum, mesenteries, omentum and retro peritoneum. In Townsend CM, Beuchamp RD, Evers BM, Mattox KL editors. Sabiston Text book of surgery, 18th Ed; vol 2. Philadelphia: Elsevier Saunders; 2008. p.1129-54

[14]. Schumpelick V. Retro muscular mesh repair for ventral incision hernia inGermany. Chirurg 2002; 73: 888-94.

[15]. Khaira HS, Lall P, Hunter B, Brown JH. Repair of incisional hernias. JR CollSurg Edinb 2001 ; 46: 39-43.

[16]. Ferranti F, Triveri P, Mancini P, Di Paola M. The treatment of large midlineincisional hernias using retro muscular prosthetic mesh (Stoppa-Rives technique).ChirrItaly 2003; 55:129-136.

[17]. Bhat MG, Somasundaram SK. Preperitoneal mesh repair of incisional hernias: Aseven-year retrospective study. Indian J Surg 2007; $69: 95-8$.

[18]. Ohana.G, Bramnik z, Miller A, Seror D, Ariche A, Belavsky R et al, treatment of large incisional abdominal wall hernias, using a modified preperitoneal prostheticmesh repair, Hernia (2006) 10:232-235.

[19]. Matapurkar BG, Gupta AK, Agarwal AK. A new technique of 'Marlex-peritonealsandwich' in the repair of large incisional hernias. World journal of surgery 1991; 15: 768-70.

[20]. Bhat MG, Somasundaram SK. Preperitoneal mesh repair of incisional hernias: Aseven-year retrospective study. Indian J Surg 2007; 69:95-8. 